\title{
Ein Ansatz zur Anwendung genetischer Algorithmen auf das Problem der Grobterminierung
}

Ulrich Weingarten, Technische Universität Braunschweig

Gegenstand der Untersuchung ist die Grobterminierung. Zugrundegelegt wird dabei das Modell von Pritsker/Watters/Wolfe ${ }^{1}$.

Aufgrund der Problemkomplexität eignen sich exakte Verfahren nur für kleinere Problemumfänge. Deterministische Heuristiken bergen das Problem, daß sie ceteris paribus in einem (sehr großen) Lösungsraum immer wieder die gleiche Lösung generieren.

Zur Überwindung dieser Nachteile wird die Anwendung des Prinzips der Genetischen Algorithmen auf das Problem der Grobterminierung vorgestellt. Gezeigt wird eine Möglichkeit der Datenrepräsentation sowie der Einfluß von drei unterschiedlichen Crossover/Reordering-Operatoren und des Operators Mutation.

Die Gene eines Chromosoms repräsentieren Arbeitsgang-BetriebsmittelKombinationen. Daraus resultiert, daß die Zustandsausprägung eines einzelnen Gens nicht mehr nur durch eine binäre ziffer dargestellt werden kann ${ }^{2}$.

Die Kombination aus Datenrepräsentation und der aus der Problemstellung resultierenden Forderung, daß jeder Arbeitsgang des zu bearbeitenden Auftragsspektrums genau einmal durchgeführt werden muß, stellt spezielle Anforderungen an den Crossover-operator. Beispielhaft wird auf die Methodik der implementierten Crossover-Operatoren (Cycle-, Order-, Partially-Matched-Crossover) eingegangen.

Die gleiche Problematik ist bei dem Entwurf des Mutations-operators zu berücksichtigen. Neben der Grundform für einen solchen Operator wird eine Variante vorgestellt, die besonders der Berücksichtigung alternativer Betriebsmittel Rechnung trägt.

1 Zur Modellierung vgl. Domschke, w.; Drexl, A.; Einführung in Operations Research, Springer-Verlag (1990), S. 94-95; Pritsker, A.B.; Watters, L.J. und Wolfe P.M.: Multiproject scheduling with limited resources: a zero-one programming approach; in: Management Science Vol. 16 (1969), No. 1, S. 93-108

2 vgl. Goldberg, David E.; Genetic Algorithms, in Search, Optimization, and Machine Learning, Reading / Mass., AddisonWesley (1989); Vignaux, G. A. und Michalewicz, z.: A Genetic Algorithm for the Linear Transportation Problem, in: IEEE Transactions on Systems, Man and Cybernetics, 21 (1991) 2, S. 445452 